\title{
Organochlorine and organophosphorus pesticide residues in raw buffalo milk from agroindustrial areas in Assiut, Egypt
}

\begin{abstract}
Raw buffalo milk samples from the agroindustrial zone in Upper Egypt were analyzed for the presence of organochlorine and organophosphorus pesticides using gas chromatography-mass spectroscopy. Five organochlorine pesticides namely, alachlor, dieldrin, hexchlorobenzene, lindane and methoxychlor and three organophosphorus pesticides chlorpyrifos, malathion, and parathion-methyl were detected in the milk samples. In $44 \%$ of the samples, the concentrations of lindane and malathion residues exceeded tolerance levels set by the European Commission (EC) in 2008. In addition, the concentrations of chlorpyrifos, methoxychlor, and hexachlorobenzene residues exceeded the 2008 EC maximum residual limits (MRLs) in $33 \%, 66 \%$, and $88 \%$ of the examined samples, respectively. However, the levels of alachlor, dieldrin, and parathion-methyl residues were below EC MRLs. The results of this study confirm the risks of pesticide residues exposure that threaten consumer health in Egypt. Thus, we recommend that pesticide residue monitoring programs be instituted in all developing countries.
\end{abstract}

Keywords: buffalo milk, GC/ms, multi pesticide residues, upper Egypt
Volume 2 Issue 5 - 2015

\author{
Eman M Shaker,' Eman E Elsharkawy \\ 'Department of Food Hygiene, Sohag University, Egypt \\ ${ }^{2}$ Department of Forensic Medicine and Toxicology, Assiut \\ University, Egypt
}

Correspondence: Eman E Elsharkawy, Department of Forensic Medicine and Toxicology, Faculty of Veterinary Medicine, Assiut University, Egypt, Tel 0020100772 8786, Fax 002088236 6503, Email medicine1971@yahoo.com

Received: October 08, 2014 | Published:September 2I, 2015

\section{Introduction}

Milk has been studied as an indicator of the bioconcentration of environmentally persistent organic micro-pollutants such as pesticides. ${ }^{1}$ Organochlorine (OC) compounds are lipophilic and metabolized very little in living organisms. Hence, environmental exposure to these compounds results in their accumulation and persistence in fat tissue. ${ }^{2}$ Moreover, OC pesticides undergo biomagnification through the food chain. ${ }^{3,4}$

Organophosphorus (OP) pesticides are esters, amides, or thiol derivatives of phosphoric or phosphonic acid. OP pesticides are easily hydrolyzed and therefore do not persist in the environment. However, their toxicity (high or moderate) and the possibility of their accumulation especially fat-soluble OPs in animal tissues, milk, and eggs pose risks for human health. ${ }^{5}$

The presence of pesticide residues in milk is a public health concern because milk and dairy products are widely consumed by infants, children, and adults. Pesticide residues in milk originate from contaminated feed, grass or corn silage, and direct application of pesticides on dairy cattle. Because humans are the last link in the food chain, they consume the highest levels of these compounds. Food products particularly dairy, meat, and fish are the primary immediate sources of OC and OP pesticide intake in the general population ${ }^{6,7}$ and these pesticides elicit a wide range of toxic and biochemical effects in both laboratory animals and wildlife. ${ }^{8,9}$ They pose serious health risks, especially in infants, who lack fully active enzymatic and metabolic systems.

To protect consumers and promote trade, maximum residue levels (MRLs) have been established for pesticide residues in products of plant and animal origin. Legislation in the European Union has established MRLs of $40 \mathrm{ng} / \mathrm{g}$ and $0.8 \mathrm{ng} / \mathrm{g}$ for the target OC pesticides dichloro-diphenyl-trichloroethane and endrin, respectively, in milk. The MRL for chlorpyrifos is $10 \mathrm{ng} / \mathrm{g} .{ }^{10}$ The governments of developing countries, however, maintain that they cannot afford to ban certain chemicals for reasons of cost, efficacy, or both. As a result, most of these chemicals have been or continue to be used in large quantities in many countries, including sub-Saharan Africa. ${ }^{11}$

Extensive soil and water pollution have been documented in Egypt, where wide use of OC pesticides in the 1960s and 1970s prompted a government ban on their use in the 1980s. ${ }^{12-14}$ However, OC pesticides are still applied widely in Egypt. ${ }^{14-16}$ Therefore, we conducted the present study to assess the current status of OC and OP pesticide residue contamination in milk, particularly since the ban on the use of these pesticides in agriculture and public health. We determined the concentration of several $\mathrm{OC}$ and $\mathrm{OP}$ pesticide residues in raw buffalo milk samples collected from various locations in the city of Assiut in Upper Egypt.

\section{Material and methods}

\section{Sampling}

A total of 45 samples of raw buffalo milk were collected at random from local vendors, dairy farms, and shops ( 15 each) between February and August 2013. These samples were obtained from three areas in the city of Assiut designated the north, middle, and south of the city. The sample unit was one original package (1L) of milk from each source. Samples were identified, placed in polypropylene bags, and immediately sent to the laboratory for analysis.

\section{Standards and reagents}

Analytical technical grade OC and OP pesticide standards with 9399\% purity were procured from Sigma-Aldrich (UK). The analytical 
OC pesticide standards included alachlor, dieldrin, hexachlorobenzene (HCB), lindane and methoxychlor. The OP pesticides analyzed in this study were chlorpyrifos, malathion and parathion-methyl. Octadecylsilyl-derivatized silica (C18), acetonitrile, petroleum ether, and anhydrous sodium sulfate were used. All reagents were of analytical (high-performance liquid chromatography) grade and were supplied by BDH (UK). The sodium sulfate was heated to $650^{\circ} \mathrm{C}$ for $4 \mathrm{~h}$ before use and stored in a desiccator. $\mathrm{C} 18$ and Florisil solid phase extraction columns were purchased from Agilent Technologies, Inc. (USA).

\section{Residue analysis}

The liquid milk samples were analyzed for OC and OP pesticide residues using a standardized multi-residue methodology according to Schenck \& Wagner ${ }^{17}$ and Lehotay et al. ${ }^{18}$

Extraction and cleanup: The extraction and cleanup method incorporated matrix solid-phase dispersion. Milk $(5.0 \mathrm{~mL})$ was blended with $2.0 \mathrm{~g} \mathrm{C} 18,2 \mathrm{~g}$ anhydrous sodium sulfate, and $1.5 \mathrm{~mL}$ acetonitrile in a syringe barrel. After the aqueous phase was removed from the column via vacuum aspiration, the pesticide residues were eluted from the C18/milk matrix with acetonitrile, which was then eluted through a Florisil solid-phase extraction column. The acetonitrile was evaporated under nitrogen, and the residue was dissolved in petroleum ether. The extract was the concentrated to $0.5 \mathrm{~mL}$ via evaporation.

Gas chromatography-mass spectrometry (GC/MS) analysis: The pesticide residues detected using GC were identified with GC/MS. GC was performed on an Agilent 7890 instrument equipped with 5975 insert ion source mass detection system (Agilent Technologies). The analytical capillary column was a DB-1701 (J\&W Scientific, USA). The column temperature was maintained at $40^{\circ} \mathrm{C}$ for $1 \mathrm{~min}$, and then programmed at $30^{\circ} \mathrm{C} / \mathrm{min}^{-1}$ up to $130^{\circ} \mathrm{C}$, then $5^{\circ} \mathrm{C} / \mathrm{min}^{-1}$ up to $250^{\circ} \mathrm{C}$, and finally $10^{\circ} \mathrm{C} / \mathrm{min}^{-1}$ up to $300^{\circ} \mathrm{C}$, which was held for $5 \mathrm{~min}$. Helium (purity, $>99.999 \%$ ) was used as the carrier gas at a flow rate of $1.2 \mathrm{~mL} / \mathrm{min}^{-1}$. The injection port temperature was $260^{\circ} \mathrm{C}$ and $1 \mu \mathrm{L}$ samples were injected splitless with the purge on after $1.5 \mathrm{~min}$. The
MS ionization energy was $70 \mathrm{eV}$, the ion-source temperature $230^{\circ} \mathrm{C}$, and the GC-MS interface temperature $280^{\circ} \mathrm{C}$. Selected ion monitoring (SIM) was used, and the dwell time of each ion was set at $100 \mathrm{~ms}$. The characteristics of the SIM method, including retention time windows and base peak ions, were designed for OC and OP pesticides. All pesticides were identified with retention time and specific ions and quantified using the external standard method.

Method validation: To determine the quality of the method, we performed a recovery study on 10 replicates of milk samples spiked with standard pesticides. The average recoveries of fortified pesticides ranged from $76.0 \%$ to $97.8 \%$ for OCs and $75.0 \%$ to $104.5 \%$ for OPs. The coefficient of variation was less than $10 \%$, indicating excellent repeatability for the method. The recovery assays were replicated five times. All samples were treated and analyzed using the GC/MSSIM procedure described above. These analyses were carried out in the analytical chemistry unit of the Pesticide Residue Laboratory at Assiut University, Egypt.

\section{Statistical analyses}

A value of zero was assigned for results below the limit of detection. The Kruskall-Wallis test was used to verify that all data were normally distributed. Data were expressed as means \pm standard error. Statistical analyses were conducted using SPSS 16.0 for Windows (SPSS, Chicago, USA). Results were considered significant at the $5 \%$ level $(\mathrm{p}<0.05)$.

\section{Results}

\section{Local vendors}

The analysis of raw buffalo milk samples from local vendors in various locations (north, middle, and south) of Assiut found chlorpyrifos and malathion in $33 \%$ of examined samples at average concentrations of $3.01 \pm 1.0$ and $0.9 \pm 0.01 \mathrm{mg} / \mathrm{kg}$, respectively. HCB was present in $66 \%$ of examined samples at an average concentration of $0.180 \pm 0.02 \mathrm{mg} / \mathrm{kg}$ (Table 1).

Table I Levels of the pesticide residues in raw buffalo milk from local vendors in various areas in Assiut city

\begin{tabular}{|c|c|c|c|c|c|c|c|}
\hline $\mathbf{N}$ & Pesticide & Area & & & & & \\
\hline \multirow[t]{2}{*}{15} & & \multicolumn{2}{|l|}{ North $n=5$} & \multicolumn{2}{|l|}{ Middle $n=5$} & \multicolumn{2}{|l|}{ South $n=5$} \\
\hline & & Range mg/kg & Average $\mathrm{mg} / \mathrm{kg}$ & Range mg/kg & Average $\mathrm{mg} / \mathrm{kg}$ & Range mg/kg & Average $\mathrm{mg} / \mathrm{kg}$ \\
\hline & $\mathrm{HCB}$ & ND & ND & $0.167-0.198$ & $0.180 \pm 0.02$ & $0.177-0.200$ & $0.189 \pm 0.02$ \\
\hline & Chlorpyrifos & $1.870-3.5 \mid 4$ & $3.01 \pm 1.0$ & ND & ND & ND & ND \\
\hline & Malathion & $0.709-0.989$ & $0.90 \pm 0.01$ & ND & ND & ND & ND \\
\hline
\end{tabular}

$\mathrm{N}$, total number of samples from local vendors; ND, non detected; $\mathrm{n}$, number of samples/each area

\section{Dairy farms}

The frequency distribution of pesticide residues detected in the analyzed buffalo milk samples obtained from dairy farms is shown in Table 2. Dieldrin, HCB, and methoxychlor were detected in $100 \%$ of the analyzed milk samples with average concentrations $(\mathrm{mg} / \mathrm{kg})$ of $0.012 \pm 0.001$ (north), $0.008 \pm 0.001$ (middle), and $0.01 \pm 0.002$ (south); $0.030 \pm 0.001$ (north), $0.030 \pm 0.001$ (middle), and $0.026 \pm 0.001$ (south); and $0.142 \pm 0.02$ (north), $0.178 \pm 0.03$ (middle), and $0.140 \pm 0.02$ (south), respectively. Lindane $(0.165 \pm 0.02 \mathrm{mg} / \mathrm{kg}$ [north] and $0.097 \pm 0.001 \mathrm{mg} /$ $\mathrm{kg}$ [south] $)$ and parathion-methyl $(0.002 \pm 0.0001 \mathrm{mg} / \mathrm{kg}$ [north] and $0.001 \pm 0.0001 \mathrm{mg} / \mathrm{kg}$ [south]) were present in $66 \%$ of the examined samples. Malathion and alachlor were present in $33 \%$ of the examined samples at average concentrations of $0.195 \pm 0.02$ and $0.001 \pm 0.0001 \mathrm{mg} / \mathrm{kg}$, respectively.

\section{Dairy shops}

We detected dieldrin, $\mathrm{HCB}$, and methoxychlor in $100 \%$ of the analyzed raw buffalo milk samples obtained from dairy shops, and they were present at average concentrations $(\mathrm{mg} / \mathrm{kg})$ of $0.014 \pm 0.001$ (north), $0.01 \pm 0.001$ (middle), and $0.012 \pm 0.001$ (south); $0.022 \pm 0.002$ (north), $0.025 \pm 0.001$ (middle), and $0.027 \pm 0.002$ (south); and $0.135 \pm 0.01$ (north), $0.198 \pm 0.01$ (middle) and $0.187 \pm 0.02$ (south), 
respectively. Lindane, chlorpyrifos, and malathion were detected in $66 \%$ of the examined samples at average concentrations $(\mathrm{mg} / \mathrm{kg})$ of $0.155 \pm 0.02$ (north) and $0.187 \pm 0.02$ (south); $0.350 \pm 0.02$ (north) and $0.289 \pm 0.02$ (south); and $0.197 \pm 0.01$ (north) and $0.190 \pm 0.02$ (south) (Table 3).

\section{Comparison with MRLs}

The levels of alachlor, dieldrin, and parathion-methyl residue in the milk samples were below the MRL values for these pesticides set by the European Commission (EC). ${ }^{19}$ However, the residue levels of lindane and malathion exceeded the permissible limit in $44 \%$ of samples, and levels of chlorpyrifos, methoxychlor, and $\mathrm{HCB}$ residue exceeded MRLs in $33 \%, 66 \%$, and $88 \%$ of the examined samples, respectively (Table 4 )

\section{Frequency distribution of pesticide residues}

The frequency distribution of pesticide residues from various sources and locations showed that dieldrin and methoxychlor pesticides were detected in $66 \%$ of the examined samples. Lindane and malathion were present in $44 \%$ of the examined samples. HCB, chlorpyrifos, parathion-methyl, and alachlor were detected in $88 \%$, $33 \%, 22 \%$ and $11 \%$ of the examined samples, respectively (Table 4 ).

Table 2 Levels of the pesticide residues in raw buffalo milk from dairy farms in various areas in Assiut city

\begin{tabular}{|c|c|c|c|c|c|c|c|}
\hline $\mathbf{N}$ & Pesticide & Area & & & & & \\
\hline \multirow[t]{2}{*}{15} & & \multicolumn{2}{|l|}{ North $n=5$} & \multicolumn{2}{|l|}{ Middle $n=5$} & \multicolumn{2}{|l|}{ South $n=5$} \\
\hline & & Range mg/kg & Average mg/kg & Range mg/kg & Average $\mathrm{mg} / \mathrm{kg}$ & Range mg/kg & Average $\mathrm{mg} / \mathrm{kg}$ \\
\hline & Alachlor & ND & ND & ND & ND & $0.000-0.001$ & $0.00 I \pm 0.000 I$ \\
\hline & Dieldrin & $0.010-0.015$ & $0.012 \pm 0.001$ & $0.006-0.009$ & $0.008 \pm 0.001$ & $0.08-0.012$ & $0.01 \pm 0.002$ \\
\hline & $\mathrm{HCB}$ & $0.027-0.033$ & $0.030 \pm 0.00 I$ & $0.028-0.032$ & $0.030 \pm 0.001$ & $0.024-0.030$ & $0.026 \pm 0.001$ \\
\hline & Lindane & $0.158-0.176$ & $0.165 \pm 0.02$ & ND & ND & $0.090-0.099$ & $0.097 \pm 0.00 \mathrm{I}$ \\
\hline & Methoxychlor & $0.137-0.180$ & $0.142 \pm 0.02$ & $0.167-0.185$ & $0.178 \pm 0.03$ & $0.137-0.145$ & $0.140 \pm 0.02$ \\
\hline & $\begin{array}{l}\text { Parathion- } \\
\text { methyl }\end{array}$ & $0.001-0.003$ & $0.002 \pm 0.000 \mathrm{I}$ & ND & ND & $0.000-0.001$ & $0.00 \mathrm{I} \pm 0.000 \mathrm{I}$ \\
\hline
\end{tabular}

$\mathrm{N}$, total number of samples from local vendors; ND, non detected; $n$, number of samples/each area

Table 3 Levels of the pesticide residues in raw buffalo milk from dairy shops in various areas in Assiut city

\begin{tabular}{|c|c|c|c|c|c|c|c|}
\hline $\mathbf{N}$ & Pesticide & Area & & & & & \\
\hline \multirow[t]{2}{*}{15} & & \multicolumn{2}{|l|}{ North $n=5$} & \multicolumn{2}{|l|}{ Middle $n=5$} & \multicolumn{2}{|l|}{ South $n=5$} \\
\hline & & Range mg/kg & Average mg/kg & Range mg/kg & Average mg/kg & Range mg/kg & Average $\mathrm{mg} / \mathrm{kg}$ \\
\hline & Dieldrin & $0.010-0.015$ & $0.014 \pm 0.001$ & $0.08-0.012$ & $0.01 \pm 0.00 I$ & 42292 & $0.012 \pm 0.00 \mathrm{I}$ \\
\hline & $\mathrm{HCB}$ & $0.019-0.023$ & $0.022 \pm 0.002$ & $0.020-0.028$ & $0.025 \pm 0.002$ & $0.023-0.029$ & $0.027 \pm 0.002$ \\
\hline & Lindane & $0.150-0.156$ & $0.155 \pm 0.02$ & ND & ND & $0.180-0.192$ & $0.187 \pm 0.02$ \\
\hline & Methoxychlor & $0.130-0.137$ & $0.135 \pm 0.01$ & $0.188-0.200$ & $0.198 \pm 0.01$ & $0.158-0.165$ & $0.16 \pm 0.02$ \\
\hline & Chlorpyrifos & $0.347-0.360$ & $0.350 \pm 0.02$ & ND & ND & $0.282-0.290$ & $0.289 \pm 0.02$ \\
\hline & Malathion & $0.188-0.200$ & $0.197 \pm 0.01$ & ND & ND & $0.185-0.190$ & $0.19 \pm 0.02$ \\
\hline
\end{tabular}

$\mathrm{N}$, total number of samples from local vendors; ND, non detected; $n$, number of samples/each area 
Table 4 Total frequency of pesticide residues studied in this work and the incidence of their levels exceeding the legalized maximum residual limits

\begin{tabular}{lllll}
\hline \multirow{2}{*}{ Pesticide } & $\begin{array}{l}\text { Number } \\
\text { analyzed }\end{array}$ & Frequency & MRL* & \multirow{2}{*}{ < } \\
\cline { 3 - 4 } & & $\mathbf{N}-(\%)$ & $\mathbf{m g} / \mathbf{k g}$ & \\
\hline Alachlor & 45 & $5-(\mathrm{II})$ & 0.01 & ----- \\
Dieldrin & 45 & $30-(66.6)$ & 0.06 & ---- \\
HCB & 45 & $40-(88.8)$ & 0.01 & 88 \\
Lindane & 45 & $20-(44.4)$ & 0.01 & 44 \\
Methoxychlor & 45 & $30-(66.6)$ & 0.01 & 66 \\
Chlorpyrifos & 45 & $15-(33.3)$ & 0.01 & 33 \\
$\begin{array}{l}\text { Malathion } \\
\text { Parathion- }\end{array}$ & 45 & $20-(44.5)$ & 0.02 & 44 \\
methyl & 45 & $10-(22.2)$ & 0.01 & ----- \\
\hline
\end{tabular}

*Pesticides for which European Union (EC Commission Regulation) No 149/2008, legislation has established maximum residue level (MRL) in milk and dairy products

$\mathrm{N}$, number of positive contaminated samples

\section{Discussion}

To aid in the protection of consumer health and elimination of unsafe food, as well as to help increase compliance with the requirements of the international food trade, we undertook this study to determine the levels of several OC and OP pesticide residues in raw buffalo milk samples collected from various parts (north, middle, and south) of the city of Assiut in upper Egypt. We detected the OC pesticide residues alachlor, dieldrin, $\mathrm{HCB}$, lindane, and methoxychlor in these samples from local vendors, dairy farms, and shops. . The total frequency distributions for these pesticides were $11 \%, 66 \%$, $88 \%, 44 \%$ and $66 \%$, respectively. Dieldrin was detected in $100 \%$ of the samples obtained from the dairy farms and shops at mean concentrations $(\mathrm{mg} / \mathrm{kg}$ ) of $0.012 \pm 0.001$ (north), $0.008 \pm 0.001$ (middle), and $0.01 \pm 0.002$ (south) and $0.014 \pm 0.001$ (north), $0.01 \pm 0.001$ (middle), and $0.012 \pm 0.001$ (south), respectively. These values are lower than the MRL $(0.06 \mathrm{mg} / \mathrm{kg})$ set by the EC19 and lower than levels measured in Ghana by Darko \& Acquaah, ${ }^{20}$ who detected an average concentration of $1.32 \pm 0.20 \mathrm{mg} / \mathrm{kg}$ in all milk samples analyzed.

Furthermore, the levels measured in our study were lower than those reported in a study conducted in Giza, Egypt, in which the mean concentration of dieldrin in raw milk was $2.966 \pm 0.135 \mathrm{mg} / \mathrm{kg}$ and the frequency was $55.5 \% .{ }^{21}$ On the contrary, Salem et al., ${ }^{22}$ detected no dieldrin residues in milk sampled in Jordan. However, the levels of dieldrin in our samples were higher than those detected in raw fresh milk sampled in Kampala markets in Uganda $(0.007 \mathrm{mg} / \mathrm{kg}){ }^{1}$

In the present study, the mean concentrations $(\mathrm{mg} / \mathrm{kg})$ of $\mathrm{HCB}$ in milk samples from local vendors was $0.180 \pm 0.02 \mathrm{mg} / \mathrm{kg}$ (middle and south); $\quad 0.030 \pm 0.001$ (north), $\quad 0.030 \pm 0.001$ (middle), and $0.026 \pm 0.001$ (south) in dairy farm samples; and $0.022 \pm 0.002$ (north), $0.025 \pm 0.001$ (middle), and $0.027 \pm 0.002$ (south) in samples from dairy shops. The total distribution was $88 \%$. The levels in our samples, especially those in local vendor samples, were higher than levels detected by Abu Donia et al., ${ }^{23}$ who reported mean concentrations of $0.162 \mathrm{mg} / \mathrm{kg}$ and a frequency of $41 \%$ in raw buffalo milk. The concentrations detected in our samples were also higher than those detected by Waliszewski et al., ${ }^{24}$ who reported that the frequency of positive samples was $84.3 \%$ with a mean concentration of $0.014 \mathrm{mg} / \mathrm{kg}$ fat. However, the frequency of HCB-positive samples in the current investigation was lower than those detected by Campoy et al. ${ }^{25}$ Heck et al., ${ }^{26}$ who reported positive frequencies of $94-100 \%$ and $100 \%$, respectively, with a mean concentration of $0.003 \mathrm{mg} / \mathrm{kg}$.

In the current study, the mean concentrations $(\mathrm{mg} / \mathrm{kg})$ of lindane were $0.165 \pm 0.02$ (north) and $0.097 \pm 0.001$ (south) in samples from dairy farms and $0.155 \pm 0.02$ (north) and $0.187 \pm 0.02$ (south) in samples from dairy shops. These levels were higher than the MRL (0.01) set by the $\mathrm{EC}^{19}$ and higher than those measured by Aman \& Bluthgen ${ }^{27}$ in Egyptian milk and those reported by Waliszewski et al., ${ }^{24}$ Heck et al., ${ }^{26}$ Darko and Acquaah, ${ }^{20}$ and Abu Donia et al., ${ }^{23}$ who detected mean concentrations of $0.009 \mathrm{mg} / \mathrm{kg}, 0.030 \mathrm{mg} / \mathrm{kg}, 0.005 \mathrm{mg} / \mathrm{kg}$, concentrations below the limit of detection, and $0.046 \mathrm{mg} / \mathrm{kg}$, respectively. However, our values resembled those measured by Battu et al. ${ }^{28}$ Furthermore, the frequency of lindane-positive samples in our study was lower than those reported by Waliszewski et al., ${ }^{24}$ Battu et al., ${ }^{28}$ and Abu Donia et al..$^{23}(80 \%, 53.3 \%$, and 50\%, respectively).

In the current study, the frequency distribution of alachlor was $11 \%$ of the samples examined, and the mean concentration was $0.001 \pm 0.0001 \mathrm{mg} / \mathrm{kg}$ in samples from dairy farms. These values were lower than the MRL (0.01) set by the EC. ${ }^{19}$ Methoxychlor residues were detected in $66 \%$ of all samples examined, with mean concentrations $(\mathrm{mg} / \mathrm{kg}$ ) of $0.142 \pm 0.02$ (north), $0.178 \pm 0.03$ (middle), and $0.140 \pm 0.02$ (south) in samples from dairy farms, and $0.135 \pm 0.01$ (north), $0.198 \pm 0.01$ (middle) and $0.187 \pm 0.02$ (south) in samples from dairy shops. These values were higher than the MRL (0.01) set by the EC.19 To our knowledge; no additional data for these two pesticides in milk are available.

The OP pesticide residues detected in raw buffalo milk sampled from local vendors, dairy farms, and shops in the present study were chlorpyrifos, malathion, and parathion-methyl. The total frequency distributions for these pesticides were $33 \%, 44 \%$, and $22 \%$, respectively. The mean concentration of chlorpyrifos detected was $3.01 \mathrm{mg} / \mathrm{kg}$ in the north area from local vendors and $0.350 \pm 0.02 \mathrm{mg} /$ $\mathrm{kg}$ (north) and $0.289 \pm 0.02 \mathrm{mg} / \mathrm{kg}$ (south) from dairy shops. The levels of chlorpyrifos in the tested samples were higher than the MRL (0.01) set by the $\mathrm{EC}^{19}$ for this pesticide.

In Italy, the main pollutants detected in samples of raw milk collected from four dairy plants in one study were acephate and chlorpyrifos. In every positive sample found, OP pesticide contamination was lower than the EC MRLs. ${ }^{29}$ A recent study of raw milk from nine Italian dairy plants found only traces of pesticide residues in approximately $4.4 \%$ of the samples analyzed. The main pollutant was chlorpyrifos. ${ }^{30}$ In Mexican milk samples, the average concentrations of 13 OP pesticide residues, including chlorpyrifos, were below established MRLs and ranged between 0.0051 and $0.0203 \mathrm{ppm}^{31}$

In the present study, the mean concentration of malathion was $0.9 \pm 0.01 \mathrm{mg} / \mathrm{kg}$ in milk samples from local vendors in the north area, $0.195 \pm 0.02 \mathrm{mg} / \mathrm{kg}$ in dairy farm samples in the north area, and $0.197 \pm 0.0 \mathrm{mg} / \mathrm{kg}$ (north) and $0.190 \pm 0.02 \mathrm{mg} / \mathrm{kg}$ (south) in samples from dairy shops. Our results were higher than those obtained by Fagnani et al., ${ }^{5}$ who detected malathion in milk at a mean concentration of $0.02 \mathrm{mg} / \mathrm{kg}$ and a positive frequency of $8.33 \%$. The levels of malathion in the samples analyzed in this study were higher than the MRL (0.02) set by the EC. ${ }^{19}$ 
In the current study, parathion-methyl was present in $66 \%$ of the examined samples from dairy farsms at mean concentrations of $0.002 \pm 0.0001 \mathrm{mg} / \mathrm{kg}$ (north) and $0.001 \pm 0.0001 \mathrm{mg} / \mathrm{kg}$ (south). These residues levels were traces compared with the MRL (0.01) set by the EC. ${ }^{19}$ In Spain, the residues of seven OP pesticides were detected in raw milk, and the percentage incidence measured was $0.83 \%$ for parathion-methyl with a range of $0.005-0.220 \mathrm{mg} / \mathrm{kg} .{ }^{32}$ Our results showed that the lowest number of detected pesticides was found in milk samples obtained from local vendors, dairy farms, and shops in the middle area, perhaps because this area is far from the agricultural zones in the north and south areas in which pesticides are applied in fields near grazing lactating animals.

According to Johansen et al., ${ }^{6}$ the main sources of pesticide residues in milk are contaminated feed, grass or corn silage, and direct application of pesticides on dairy cattle in barns or dairy plants. Regardless of area, the lowest number of detected pesticides was found in samples from local vendors, but these samples had high mean values of residues chlorpyrifos, malathion, and $\mathrm{HCB}$ in particular This finding may be attributed to the replacement of OC pesticides by OP pesticides in cattle dips using acaricide. ${ }^{33}$ In addition, HCB is found as an impurity in some industrial chlorination processes and is a by-product of combustion processes as well, and these are probably the main sources of environmental contamination. ${ }^{22}$ These facts may explain the high frequency of HCB-positive samples in the present study, as well as the high mean levels of residues in the samples from local vendors, where products are exposed extensively to combustion processes in the open streets where they are transferred or prepared. Several OC and OP pesticide residues were detected in raw buffalo milk samples collected from various sources and areas of the city of Assiut. The residue levels of lindane and malathion exceeded EC MRLs $^{19}$ in $44 \%$ of the samples. In addition, the residue levels of chlorpyrifos, methoxychlor, and HCB exceeded EC MRLs ${ }^{19}$ in 33\%, $66 \%$, and $88 \%$ of the examined samples, respectively. The results of this survey demonstrate the need to establish pesticide residue monitoring programs in milk for human consumption to improve food safety and decrease exposure risks for consumers.

\section{Acknowledgements}

None.

\section{Conflict of interest}

Author declares that there is no conflict of interest.

\section{References}

1. Kampire E, Kiremire BT, Nyanzi SA, et al. Organochlorine pesticide in fresh and pasteurized cow's milk from Kampala markets. Chemosphere. 2011;84(7):923-927.

2. Falandysz J, Wyrzkowska B, Warzocha J, et al. Organochlorine pesticides and PCBs in perch Perca fluviatilis from the Odra/Oder river estuary, Baltic sea. Food Chem. 2004;87(1):17-23.

3. Angulo R, Martínez P, Jodral ML. PCB congeners transferred by human milk, with an estimate of their daily intake. Food Chem Toxicol. 1999;37(11):11081-11088.

4. Borgå K, Gabrielsen GW, Skaare JU. Biomagnification of organochlorines along a Barents Sea food chain. Environ Pollut. 2001;113(2):187-198.

5. Fagnani R, Beloti V, Battaglini APP, et al . Organophosphorus and carbamates residues in milk and feedstuff supplied to dairy cattle. Pesq Vet Bras. 2011;31(7):598-602.
6. Johansen P, Muir D, Asmund G, et al. Human exposure to contaminants in the traditional Greenland diet. Sci Total Environ. 2004;331(1-3):189-206.

7. Schecter A, Cramer P, Boggess K, et al. Levels of dioxins, dibenzofurans, PCB and DDE congeners in pooled food samples collected in 1995 at supermarkets across the United States. Chemosphere. 1997;34(5-7):1437-1447.

8. Fox GA, Kennedy SW, Norstrom RJ, et al. Porphyria in herring gulls: a biochemical response to chemical contamination of Great Lakes food chains. Environ. Toxicol Chem. 1988;7(10):831-839.

9. Safe S. Polychlorinated biphenyls (PCBs), dibenzo-p-dioxins (PCDDs), dibenzofurans (PCDFs), and related compounds: environmental and mechanistic considerations which support the development of toxic equivalency factors (TEFs). Critical Rev Toxicol. 1990;21(1):51-88.

10. EU European Commission. DG Health and Consumer Protection, Draft Annexes to Regulation 396/2005: Annex I, II, III and IV. 2007.

11. Ullah R, Malik RN, Muhammad A, et al. Assessment of selected persistent organic pollutants (POPs) in sediments from streams of Sialkot district. The BIOL. 2010;1:7-15.

12. Ahmed SA. Side effects of herbicides. Proceedings of the First Third World Conference on Environmental and Health Hazards of Pesticides. Cairo, Egypt: Cairo Univ Press; 1989;83-99.

13. El-Sebae AH, Soliman SA. Mutagenic and carcinogenic chemicals in the Egyptian agricultural environment. Basic Life Sci. 1982;21:119-126.

14. Soliman AS, Smith MA, Cooper SP, et al. Serum organochlorine pesticide levels in patients with colorectal cancer in Egypt. Arch Environ Health. 1997;52(6):409-415.

15. Amr MM, Moursy AW, Hafez RS, et al. Pesticide residues in milk and dairy products in Egypt. Egypt J Occup Med. 1995;19:147-168.

16. Dogheim SM, Nasr EN, Almaz MM, et al. Pesticide residues in milk and fish samples collected from two Egyptian governorates. J Assoc Off Anal Chem. 1990;73(1):19-21.

17. Schenck FJ, Wagner R. Screening procedure for organochlorine and organophosphorus pesticide residues in milk using matrix solid phase dispersion (MSPD) extraction and gas chromatographic determination. Food Addit Contam. 1995;12(4):535-541.

18. Lehotay SJ, Mastovská K, Yun SJ. Evaluation of two fast and easy methods for pesticide residue analysis in fatty food matrices. $J A O A C$ Int. 2005;88(2):630-638.

19. EC (Commission Regulation) No 149/2008 of 29 January 2008 amending Regulation (EC) No 396/2005 of the European Parliament and of the Council by establishing Annexes II, III and IV setting maximum residue levels for products covered by Annex I (Official Journal L58/1,1.3.2008)

20. Darko G, Acquaah SO. Levels of organochloride pesticides residues in dairy products in Kumasi, Ghana. Chemosphere. 2008;71:294-298.

21. Ahmed NS, Zaki EMS. Detection of some organochlorine pesticides in raw milk in Giza governorate. J Appl Sci Res. 2009;5:2520-2523.

22. Salem NM, Ahmad R, Estaitieh H. Organochlorine pesticide residues in dairy products in Jordan. Chemosphere. 2009;77(5):673-678.

23. Abou-Donia MA, Abou-Arab Enb A, El-Senaity MH, et al. Chemical composition of raw milk and the accumulation od pesticide residues in milk products. Global Veterinaria. 2010;4(1):06-14.

24. Waliszewski SM, Pardío VT, Waliszewski KN, et al. Organochlorine pesticide residues in cow's milk and butter in Mexico. Sci Total Environ. 1997;208(1-2):127-132. 
25. Campoy C, Jiménez M, Olea-Serrano MF, et al. Analysis of organochlorine pesticides in human milk: preliminary results. Early Hum Dev. 2001;65:S183-S190

26. Heck MC, Santos JS, Bogusz Tunior S, et al. Estimation of children exposure to organochlorine compounds through milk in Rio Grando Do Sul, Brazil. Food Chem. 2007;102(1):288-294.

27. Aman IM, Bluthgen A. Occurrence of residues of organochlorine pesticides and polychlorinated biphenyls in milk and dairy products from Egypt. Milchwissenschaft-Milk Sci Int. 1997;52:394-399.

28. Battu RS, Singh B, Kang BK. Contamination of liquid milk and butter with pesticide residues in the Ludhiana district of Punjab State, India. Ecotoxicol Environ Saf. 2004;59(3):324-331.
29. Pagliuca G, Serraino A, Gazzotti T, et al. Organophosphorus pesticides residues in Italian raw milk. J Dairy Res. 2006;73(3):340-344.

30. Gazzotti T, Sticca P, Zironi E, et al. Determination of 15 organophosphorus pesticides in Italian raw milk. Bull Environ Contam Toxicol. 2009;82(2):251-254.

31. Salas JH, González MM, Noa M, et al. Organophosphorus Pesticide Residues in Mexican Commercial Pasteurized Milk. J Agric Food Chem. 2003;51(15):4468-4471.

32. Melgar MJ, Santaeufemia M, Garcia MA. Organophosphorus pesticide residues in raw milk and infant formulas from Spanish northwest. $J$ Environ Sci Health B. 2010;45(7):595-600.

33. Kateregga J. Deltamethrin and Chlorfenvinphos Residues in Milk of Sprayed Cows in Mukono County-Uganda. Makerere University. 2000. 